\title{
Nguyên tắc bồi thường thiệt hại do vi phạm hợp đồng
}

\author{
Bùi Thị Thanh Hằng* \\ Khoa Luật, Đại học Quốc gia Hà Nội, 144 Xuân Thủy, Cầu Giấy, Hà Nội, Việt Nam \\ Nhận ngày 09 tháng 4 năm 2017 \\ Chỉnh sửa ngày 26 tháng 5 năm 2017; Chấp nhận đăng ngày 28 tháng 6 năm 2017
}

\begin{abstract}
Tóm tắt: Nguyên tắc bồi thường toàn bộ là nguyên tắc được khoa học pháp lý thế giới cũng như Việt Nam thừa nhận. Nguyên tắc này là hệ luận của nguyên tắc "pacta sunt servanda", theo đó, bên có quyền phải được bồi thường toàn bộ những thiệt hại mà bên này phải gánh chịu. Trong phạm vi bài viết này, tác giả sẽ đề cập đến nguyên tắc bồi thường toàn bộ và các trường hợp ngoại lệ của nguyên tắc bồi thường toàn bộ.
\end{abstract}

Tư khóa: Nguyên tắc bồi thường toàn bộ, nguyên tắc pacta sunt servanda, Bộ luật Dân sự năm 2015.

\section{1. Đặt vấn đề}

Dựa trên nguyên tắc pacta sunt servanda, bên có quyền có quyền yêu cầu bên có nghĩa vụ phải thực hiện đúng cam kết trong hợp đồng. Trong trường hợp bên có nghĩa vụ không thực hiện đúng hợp đồng gây thiệt hại cho bên có quyền thì bên có quyền có quyền yêu cầu bên có nghĩa vụ bồi thường thiệt hại cho những tổn thất mà bên này phải gánh chịu. Với bản chất buộc bên vi phạm hợp đồng phải trả một khoản tiền nhất định cho bên bị thiệt hại nhằm đưa bên bị thiệt hại vào vị trí mà bên này đáng lẽ đạt được nếu hợp đồng được thực hiện đúng, có thể nhận thấy bồi thường thiệt hại có ý nghĩa thay thế nghĩa vụ phải thực hiện đúng hợp đồng bằng nghĩa vụ phải trả một khoản tiền tương ứng với thiệt hại mà bên bị thiệt hại phải gánh chịu trong trường hợp bên có nghĩa vụ đã không thực hiện đúng nghĩa vụ mà đáng lẽ bên này phải thực hiện - bồi thường toàn bộ thiệt

\footnotetext{
*ĐT.: 84-904158709.

Email: hangbttvnu@gmail.com

https://doi.org/10.25073/2588-1167/vnuls.4099
}

hại. Có thể nhận thấy nguyên tắc bồi thường toàn bộ là hệ luận của nguyên tắc "pacta sunt servanda", theo đó, bên có quyền phải được bồi thường toàn bộ những thiệt hại mà bên này phải gánh chịu. Đây là nguyên tắc được khoa học pháp lý thế giới cũng như Việt Nam thừa nhận. Trong phạm vi bài viết này, tác giả sẽ đề cập đến nguyên tắc bồi thường toàn bộ và các trường hợp ngoại lệ của nguyên tắc bồi thường toàn bộ.

\section{Nguyên tắc bồi thường toàn bộ thiệt hại}

Bồi thường thiệt hại do vi phạm hợp đồng trong hệ thống civil law mà tiêu biểu là Pháp được xây dựng trên cơ sở bồi thường thiệt hại theo truyền thống luật La Mã. Theo luật La Mã khoản bồi thường thiệt hại đầy đủ bao gồm khoản bồi thường thiệt hại cho "damnum emergens" và "lucrum cessans". "Damnum emergens" được hiểu là tổn thất thực tế mà bên bị thiệt hại phải gánh chịu - những tổn thất mà bên bị thiệt hại phải gánh chịu là hậu quả của việc bên kia không thực hiện hợp đồng. 
"Lucrum cessans" được hiểu là khoản lợi bị mất - những khoản lợi mà bên bị thiệt hại đáng lẽ có được nếu hợp đồng được thực hiện đúng. Hai loại thiệt hại này cũng được các học giả Pháp xem là cơ sở để xác định khoản bồi thường thiệt hại do vi phạm hợp đồng. Điều này được thể hiện rõ thông qua quy định của Điều 1149 Bộ luật Dân sự Pháp năm 1804 và nay được ghi nhận tại Điều 1231-2 Sắc lệnh số 2016-131 với quy định: "Về nguyên tắc, giá trị khoản bồi thường cho bên có quyền bao gồm thiệt hại thực tế và lợi ích mà lẽ ra bên có quyền được hưởng,..." Như vậy, mặc dù nguyên tắc bồi thường toàn bộ không được ghi nhận minh thị trong Bộ luật Dân sự Pháp nhưng dựa trên tư tưởng thiệt hại phải được khắc phục hoàn toàn và nội dung của Điều 1149 Bộ luật Dân sự Pháp năm 1804 cũng như Điều 1231-2 Sắc lệnh số 2016-131 có thể khẳng định nguyên tắc bồi thường toàn bộ (Principe de la réparation intégrale) được xem là nguyên tắc cơ bản trong luật hợp đồng Pháp [1].

Ở Anh trước thế kỷ XIX các phán quyết về bồi thường thiệt hại do vi phạm hợp đồng rất khác nhau bởi lúc đó luật hợp đồng Anh chưa đưa ra nguyên tắc xác định bồi thường thiệt hại và quyền quyết định mức bồi thường thiệt hại hoàn toàn thuộc về bồi thẩm đoàn [2]. Đến thế kỷ XIX, do chịu ảnh hưởng của pháp luật Pháp, nguyên tắc bồi thường thiệt hại trong luật hợp đồng Anh mới được rút ra từ tuyên bố của thẩm phán Baron Parke trong vụ Robinson kiện Harman. Theo nội dung vụ kiện, Harman đã đồng ý cho Robinson thuê nhà cùng tài sản trong ngôi nhà trong thời hạn 21 năm. Mặc dù Robinson đã chấp nhận nhưng sau đó Harman không giao nhà cho Robinson. Do vậy, Robinson khởi kiện đòi Harman phải bồi thường thiệt hại đối với tổn thất thực tế, khoản lợi bị mất và những chi phí cho việc chuẩn bị thuê nhà. Thẩm phán Baron Parke đã tuyên bố: "Quy tắc của common law về bồi thường thiệt hại là bên bị vi phạm sẽ được đặt vào tình trạng tương tự như khi hợp đồng được thực hiện đúng nếu thiệt hại do vi phạm hợp đồng có thể được bù đắp bằng tiền" [3]. Như vậy, có thể nhận thấy nguyên tắc bồi thường thiệt hại của Anh là tương tự nguyên tắc bồi thường thiệt hại của Pháp - nguyên tắc bồi thường toàn bộ. Tuy nhiên, vào thời điểm rút ra nguyên tắc bồi thường toàn bộ thiệt hại, luật hợp đồng Anh chưa đưa ra tiêu chí để xác định mức bồi thường thiệt hại và phải đến năm 1936, luật hợp đồng Anh mới đưa ra ba tiêu chí xác định khoản bồi thường thiệt hại theo sáng kiến của Lon L. Fuller và William R. Perdue.

Trên bình diện quốc tế, mặc dù được thể hiện ở những mức độ khác nhau nhưng nguyên tắc bồi thường toàn bộ thiệt hại được phản ánh trong cả Công ước của Liên hợp quốc về hợp đồng mua bán hàng hóa quốc tế năm 1980 (CISG), Bộ nguyên tắc của UNIDROIT về hợp đồng thương mại quốc tế (UPICC) và Bộ nguyên tắc về luật hợp đồng châu Âu (PECL). Nguyên tắc bồi thường toàn bộ thiệt hại được ghi nhận tại Điều 74 CISG. Điều 74 CISG không trực tiếp ghi nhận nguyên tắc bồi thường toàn bộ thiệt hại mà đưa ra nguyên tắc bồi thường thiệt hại áp dụng chung cho cả bên mua và bên bán. Theo đó, bên bị thiệt hại có thể yêu cầu bên gây thiệt hại phải bồi thường "một khoản tiền tương ứng với những tổn thất, gồm cả lợi nhuận bị mất mà bên bị thiệt hại phải gánh chịu... là hệ quả của hành vi vi phạm hợp đồng." Như vậy, có thể nói nguyên tắc bồi thường toàn bộ thiệt hại đã được ghi nhận trong CISG thông qua việc ghi nhận thiệt hại được bồi thường áp dụng chung cho cả bên mua và bên bán không chỉ bao gồm tổn thất thực tế mà còn bao gồm cả lợi ích bị mất.

Khác với CISG, UPICC thay vì ghi nhận một cách ngầm định nguyên tắc bồi thường toàn bộ đã minh thị ghi nhận nguyên tắc này tại Điều 7.4.2 dưới tiêu đề "full compensation (bồi thường toàn bộ)". Theo đó Điều 7.4.2(1) UPICC nêu rõ: "Bên bị vi phạm được bồi thường toàn bộ thiệt hại mà mình phải gánh chịu là hệ quả của việc không thực hiện hợp đồng". Mặt khác, cũng tại điều khoản này UPICC còn giải thích "toàn bộ thiệt hại" được hiểu là bao gồm “... những tổn thất mà bên bị thiệt hại phải gánh chịu và những lợi ích bị mất đi...". 
Tương tự như CISG, PECL cũng gián tiếp ghi nhận nguyên tắc bồi thường toàn bộ thông qua quy định chung về cách tính thiệt hại được bồi thường tại Điều 9:502 PECL. Theo đó, một mặt Điều 9:502 PECL đưa ra nguyên tắc bồi thường thiệt hại là đưa bên bị thiệt hại vào vị trí gần nhất với vị trí mà bên này đáng lẽ đạt được nếu hợp đồng được thực hiện đúng thông qua việc bù đắp một khoản tiền. Đây là cách tiếp cận của các quốc gia thuộc hệ thống common law. Mặt khác, tương tự như Điều 74 CISG và Điều 7.4.2 UPICC, Điều 9:502 PECL cũng chỉ rõ thiệt hại được bồi thường bao gồm "những tổn thất mà bên bị thiệt hại phải gánh chịu và những lợi ích bị mất" - đây cũng chính là cách tiếp cận của các quốc gia thuộc hệ thống civil law. Theo quy định của Điều 9:502 PECL, có thể nhận thấy quy định của điều khoản này không chỉ thể hiện quan điểm của hệ thống common law mà còn thể hiện cả quan điểm của hệ thống civil law.

Như vậy, nguyên tắc bồi thường toàn bộ được cả ba văn bản pháp lý quốc tế quan trọng về hợp đồng cũng như hai hệ thống pháp luật chính mà đại diện là Pháp và Anh ghi nhận với một triết lý nhất quán là đặt bên bị thiệt hại vào vị trí kinh tế mà bên này đáng lẽ đạt được nếu hợp đồng được thực hiện đúng. Nói cách khác, nguyên tắc bồi thường toàn bộ là nguyên tắc đặt bên có quyền (bên bị thiệt hại) vào vị trí tương tự như vị trí khi bên có nghĩa vụ (bên vi phạm) tuân thủ đúng các điều khoản của hợp đồng mà các bên đã tự nguyện xác lập.

Xuất phát từ mục đích của bồi thường thiệt hại là khắc phục những hậu quả do hành vi không thực hiện đúng hợp đồng gây ra, hệ thống pháp luật Việt Nam cũng ghi nhận nguyên tắc bồi thường thiệt hại do vi phạm nghĩa vụ nói chung và bồi thường thiệt hại do vi phạm hợp đồng nói riêng là bồi thường toàn bộ thiệt hại mà bên bị thiệt hại phải gánh chịu. Nguyên tắc này được ghi nhận minh thị tại Điều 360 Bộ luật Dân sự năm 2015: "Trường hợp có thiệt hại do vi phạm nghĩa vụ gây ra thì bên có nghĩa vụ phải bồi thường toàn bộ thiệt hai,...". Bên cạnh việc chỉ ra minh thị nguyền tắc bồi thường thiệt hại trong hệ thống pháp luật
Việt Nam là bồi thường toàn bộ, Bộ luật Dân sự năm 2015 còn chỉ rõ thiệt hại được bồi thường không chỉ có thiệt hại về vật chất mà còn có thiệt hại về tinh thần. Khác với Bộ luật Dân sự năm 2015, Luật Thương mại năm 2005 không minh thị đưa ra nguyên tắc bồi thường thiệt hại nhưng với quy định tại khoản 2 Điều 302: "Giá trị bồi thường thiệt hại bao gồm giá trị tổn thất thực tế, trực tiếp mà bên bị vi phạm phải chịu do bên vi phạm gây ra và khoản lợi trực tiếp mà bên bị vi phạm đáng lẽ được hưởng nếu không có hành vi vi phạm", có thể nhận thấy Luật Thương mại năm 2005 có cách tiếp cận tương tự như Điều 74 CISG.

Như vậy, Bộ luật Dân sự năm 2015 và Luật Thương mại năm 2005 mặc dù có sự khác biệt trong việc ghi nhận nguyên tắc bồi thường thiệt hại cũng như tiêu chí xác định mức bồi thường thiệt hại nhưng cả hai văn bản pháp luật quan trọng của luật tư Việt Nam đều ghi nhận nguyên tắc bồi thường thiệt hại là bồi thường toàn bộ các thiệt hại là hậu quả của hành vi không thực hiện đúng hợp đồng.

\section{Ngoại lệ của nguyên tắc bồi thường toàn bộ}

Tuy có vai trò là nguyên tắc cơ bản của chế định bồi thường thiệt hại trong các hệ thống pháp luật nêu trên nhưng không phải trong mọi trường hợp nguyên tắc bồi thường toàn bộ cũng được áp dụng một cách tuyệt đối hay nói cách khác là nguyên tắc "pacta sunt servanda" không còn vị trí tuyệt đối mà đã có sự mềm dẻo hóa thông qua việc thừa nhận một số trường hợp bên không thực hiện đúng hợp đồng gây ra thiệt hại cho bên bị vi phạm có thể được miễn, giảm trách nhiệm bồi thường thiệt hại. Trong đó giảm trách nhiệm bồi thường thiệt hại được xem là một biến thể của miễn trách nhiệm bồi thường [4]. Sau đây trong bài viết sử dụng thuật ngữ chung là miễn trách nhiệm bồi thường thiệt hại.

Khoa học pháp lý thế giới cũng như Việt Nam thừa nhận các trường hợp miễn trách nhiệm bồi thường thiệt hại gồm: miễn trách nhiệm theo thỏa thuận; miễn trách nhiệm do 
thiệt hại xảy ra là do lỗi của bên bị thiệt hại, miễn trách nhiệm do xuất hiện sự kiện pháp lý nằm ngoài dự kiến của các bên vào thời điểm xác lập hợp đồng.

Việc thừa nhận miễn trách nhiệm bồi thường thiệt hại theo thỏa thuận là xuất phát từ nguyên tắc tôn trọng tự do ý chí, tự nguyện cam kết, thỏa thuận của các bên. Trong khi đó việc thừa nhận miễn trách nhiệm bồi thường thiệt hại không dựa trên thỏa thuận xuất phát từ nhận thức việc áp dụng cứng nhắc nguyên tắc "pacta sunt servanda" trong trường hợp thiệt hại xảy ra do lỗi của bên có quyền, hoặc thiệt hại xảy ra nằm ngoài tầm kiểm soát của bên có nghĩa vụ là trái với công lý và tạo ra sự bất công. Vai trò bảo vệ công lý của miễn trách nhiệm bồi thường thiệt hại trong trường hợp xuất hiện tình huống bất thường dẫn đến hợp đồng không thể thực hiện được hoặc trở nên vô nghĩa hoặc phá hủy nghiêm trọng sự cân bằng về kinh tế giữa các bên thể hiện ở chỗ không buộc bên không thực hiện đúng hợp đồng phải bồi thường thiệt hại.

Hệ quả của miễn trách nhiệm bồi thường thiệt hại là bên có hành vi không thực hiện đúng hợp đồng không phải bồi thường thiệt hại hoặc chỉ phải bồi thường một phần thiệt hại xảy ra, nói cách khác hệ quả của việc miễn trách nhiệm bồi thường thiệt hại là bên bị vi phạm không được nhận khoản bồi thường tương ứng với thiệt hại mà họ phải gánh chịu, cho dù có thể chứng minh thiệt hại xảy ra.

Xuất phát từ nguyên tắc tự do ý chí, các hệ thống pháp luật đều cho phép các bên thỏa thuận về điều khoản miễn trách nhiệm bồi thường thiệt hại. Điều đó có nghĩa là khi thỏa thuận về miễn trách nhiệm bồi thường thiệt hại được đưa vào hợp đồng thì thỏa thuận đó sẽ có hiệu lực đối với các bên. Ở Pháp điều khoản miễn trừ chỉ được áp dụng bởi Tòa án đối với hợp đồng mẫu nhằm ngăn chặn việc bên có lợi thế đưa vào hợp đồng những điều khoản bất lợi cho bên kia. Luật hợp đồng Anh cho phép miễ்n trách nhiệm bồi thường thiệt hại khi bên không thực hiện đúng hợp đồng viện dẫn tới những sự kiện dẫn tới hợp đồng "không thể thực hiện được" đã được các bên dự liệu trong điều khoản miễn để làm căn cứ miễn trách nhiệm bồi thường thiệt hại. Việc viện dẫn đến các sự kiện đã nêu trong điều khoản miễn do các bên đưa vào hợp đồng cũng có thể được kết hợp với những sự kiện dẫn tới mục đích của hợp đồng không đạt được dù hợp đồng được thực hiện cũng được xem là căn cứ miễn trách nhiệm bồi thường thiệt hại trong luật hợp đồng Anh [5].

Trong hệ thống pháp luật Việt Nam, trường hợp này thỏa thuận về điều khoản miễn trách nhiệm bồi thường thiệt hại được ghi nhận tại Điều 360 Bộ luật Dân sự năm 2015 và điểm a khoản 1 Điều 294 Luật Thương mại năm 2005. Điều này cho thấy luật hợp đồng Việt Nam rất coi trọng nguyên tắc tự do ý chí. Do vậy về nguyên tắc, thỏa thuận miễn trách nhiệm bồi thường thiệt hại được thực hiện vào thời điểm xác lập hợp đồng nhưng các bên cũng có thể đạt được thỏa thuận về miễn trách nhiệm bồi thường thiệt hại sau thời điểm đó. Có thể nhận thấy quy định về thỏa thuận miễn trách nhiệm bồi thường thiệt hại trong luật hợp đồng Việt Nam dường như còn thiếu chặt chẽ bởi không đặt ra giới hạn đối với thỏa thuận miễn trách nhiệm bồi thường thiệt hại của các bên và do đó có thể dẫn đến sự bất công cho một bên khi bên được miễn trách nhiệm lợi dụng điều khoản này cố ý vi phạm hợp đồng [6]. Kinh nghiệm quốc tế cho thây, các hệ thống pháp luật đều đặt ra giới hạn đối với miễn trách nhiệm dựa trên thỏa thuận, theo đó bên vi phạm hợp đồng sẽ không được miễn trách nhiệm nếu cố ý vi phạm hoặc vô ý nghiêm trọng trong việc không thực hiện đúng hợp đồng [7], hoặc nếu áp dụng điều khoản miễn trách nhiệm bồi thường thiệt hại do các bên thỏa thuận sẽ gây nên sự bất bình đẳng [8]... Như vậy sẽ là hoàn thiện hơn nếu pháp luật Việt Nam một mặt thừa nhận quyền thỏa thuận về miễn trách nhiệm của các bên trong hợp đồng, mặt khác đặt ra giới hạn đối với trường hợp này.

Ngoài việc ghi nhận trường hợp miễn trách nhiệm dựa trên thỏa thuận của các bên, CISG, UPICC và PECL còn ghi nhận các trường hợp miễn trách nhiệm bồi thường thiệt hại không dựa trên sự thỏa thuận của các bên gồm: việc không thực hiện đúng hợp đồng là do trở ngại 
khách quan, việc không thực hiện đúng hợp đồng do lỗi của bên bị vi phạm [9] hoặc do lỗi của người thứ ba [10].

Mặc dù đã có nhiều tranh luận trước đây nhưng hiện nay khoa học pháp lý thế giới đã thừa nhận quy định về miễn trách nhiệm tại Điều 79 CISG không chỉ được áp dụng đối với những trở ngại là sự kiện bất khả kháng (force majeure) mà còn được áp dụng cho trường hợp hardship [11]. Nói cách khác, những "trở ngại (impediment)" theo Điều 79 CISG bao gồm cả sự kiện "force majeure" và sự kiện "hardship".

Bất khả kháng (force majeure) là khái niệm chỉ những trường hợp có sự thay đổi của hoàn cảnh (trở ngại) nằm ngoài kiểm soát của bên có nghĩa vụ dẫn tới việc bên có nghĩa vụ không thể thực hiện được hợp đồng, do đó bên có nghĩa vụ không phải chịu rủi ro mà những trở ngại này mang lại. Căn cứ miễn trách nhiệm này được ghi nhận tại Điều 79 CISG, Điều 7.1.7 UPICC và Điều 8:108 PECL.

Tiêu chí đánh giá một trở ngại có phải là sự kiện bất khả kháng hay không là xem xét những trở ngại dẫn đến việc không thực hiện đúng hợp đồng có vượt quá khả năng kiểm soát của bên không thực hiện đúng hợp đồng hay không, bên không thực hiện đúng hợp đồng có thể dự liệu được sự xuất hiện của trở ngại này vào thời điểm xác lập hợp đồng hay không và bên này có thể tránh được hoặc khắc phục được trở ngại cũng như hậu quả do trở ngại đó gây ra hay không. Nếu bên không thực hiện đúng hợp đồng có khả năng kiểm soát trở ngại hoặc dự liệu được trở ngại vào thời điểm xác lập hợp đồng hoặc có khả năng tránh được/ khắc phục được trở ngại cũng như hậu quả do trở ngại gây ra thì trở ngại đó không được xem là sự kiện bất khả kháng. Có nghĩa là nếu bên vi phạm hợp đồng trước đó cam kết sẽ thực hiện đúng hợp đồng ngay cả khi có trở ngại hoặc dự liệu được trở ngại đó có thể xảy ra thì bên này sẽ vẫn phải chịu trách nhiệm bồi thường thiệt hại kể cả khi đã nỗ lực hết mức để đạt được kết quả đã cam kết. Sự kiện bất khả kháng có thể là những trở ngại thuộc hiện tượng thiên nhiên như lũ lụt, hỏa hoạn, động đất, sóng thần... hoặc cũng có thể là những biến động trong xã hội như chiến tranh, đảo chính, đình công, cấm vận,...

"Hardship" là khái niệm chỉ đến trường hợp mà sự thay đổi của hoàn cảnh mặc dù không dẫn đến hợp đồng không thể thực hiện được nhưng khiến việc thực hiện hợp đồng đó trở nền vô nghĩa hoặc phá hủy nghiêm trọng sự cân bằng về kinh tế giữa các bên.

Do "hardship" và "force majeure" đều được xác định dựa trên hai tiêu chí cơ bản: trở ngại dẫn đến việc không thực hiện đúng hợp đồng nằm ngoài tầm kiểm soát của bên vi phạm hợp đồng; và bên vi phạm hợp đồng không thể dự liệu được sự xuất hiện của trở ngại dẫn đến việc không thực hiện đúng hợp đồng nên trong nhiều trường hợp ranh giới giữa "hardship" và "force majeure" không thật sự rõ ràng. Do đó, nhiều trường hợp các bên trong hợp đồng có thể lựa chọn việc viện dẫn áp dụng "hardship" hoặc "force majeure" tùy thuộc vào mong muốn của các bên về việc chấm dứt hợp đồng hay điều chỉnh hợp đồng để tiếp tục thực hiện [12]. Tuy nhiên, khác với force majeure, việc xác định "hardship" còn đòi hỏi phải đáp ứng thêm một tiêu chí là việc thực hiện hợp đồng sẽ làm thay đổi căn bản nền tảng của hợp đồng dẫn đến sự mất cân bằng nghiêm trọng về lợi ích giữa các bên trong hợp đồng. Do vậy, có quan điểm cho rằng "hardship" là trường hợp đặc biệt của "force majeure" nhưng có hệ quả pháp lý linh hoạt hơn [13].

Ở Pháp, trước thời điểm Sắc lệnh số 2016131 có hiệu lực, luật hợp đồng Pháp ghi nhận ba trường hợp miễn trách nhiệm bồi thường thiệt hại không dựa trên thỏa thuận của các bên gồm: miễn trách nhiệm do bất khả kháng (force majeure), miễn trách nhiệm do lỗi của bên có quyền và miễn trách nhiệm do lỗi của người thứ ba [14]. Tuy nhiên, Sắc lệnh số 2016-131 về cải cách luật nghĩa vụ của Pháp dựa trên án lệ đã bổ sung một trường hợp miễn trách mới là sự kiện "imprévision (không thể dự đoán trước)" [15] và bổ sung khái niệm "force majeure" thông qua việc đưa ra các tiêu chí để xác định một trở ngại là bất khả kháng [16]. 
Khác với CISG, UPICC, PECL và luật hợp đồng Pháp, luật hợp đồng Anh không thừa nhận khái niệm "hardship" bởi Anh không cho phép Tòa án điều chỉnh hợp đồng khi có sự thay đồi của hoàn cảnh và xuất phát từ quan điểm cho rằng hợp đồng là tối thượng [17]. Về phương diện lịch sử, do trách nhiệm hợp đồng trong hệ thống common law nói chung và của Anh nói riêng là trách nhiệm nghiêm ngặt nên luật hợp đồng Anh ban đầu không công nhận những sự kiện dẫn đến việc hợp đồng không thể thực hiện được là căn cứ miễn trách nhiệm bồi thường thiệt hại. Phải đến cuối thế kỷ XIX, Anh mới đưa ra những khái niệm có vai trò tương tự như "force majeure" là "không thể thực hiện được (impossibility)" và "không đạt được mục đích (frustration)" [18]. Trong đó, "không đạt được mục đích (frustration)" là căn cứ cho phép miễn trách nhiệm bồi thường thiệt hại khi xuất hiện những sự kiện dẫn đến việc cho dù có thực hiện hợp đồng thì mục đích của hợp đồng vẫn không đạt được. Có thể nhận thấy thuật ngữ "frustration" trong luật hợp đồng Anh là thuật ngữ tương đương với thuật ngữ "force majeure" trong luật hợp đồng Pháp [19].

Tương tự như CISG, UPICC và PECL, luật hợp đồng Việt Nam bên cạnh việc ghi nhận trường hợp miễn trách nhiệm dựa trên thỏa thuận của các bên còn ghi nhận các căn cứ miễn trách nhiệm bồi thường thiệt hại không dựa trên thỏa thuận trong cả Bộ luật Dân sự và Luật Thương mại. Trong đó, miễn trách nhiệm do sự kiện bất khả kháng [20], miễn trách nhiệm do việc không thực hiện đúng hợp đồng do lỗi của bên vi phạm là những trường hợp được cả Bộ luật Dân sự năm 2015 và Luật Thương mại năm 2005 ghi nhận [21]. Luật Thương mại năm 2005 ngoài việc ghi nhận các trường hợp đó còn ghi nhận trường hợp miễn trách nhiệm khi hành vi vi phạm hợp đồng của một bên là do thực hiện quyết định của cơ quan quản lý nhà nước có thẩm quyền [22]. Như vậy so với các văn bản pháp lý quốc tế, ngoại trừ chưa có quy định cụ thể về miễn trách nhiệm bồi thường thiệt hại do việc không thực hiện đúng hợp đồng là do lỗi của bên thứ ba, có thể nói các căn cứ miễn trách nhiệm bồi thường thiệt hại được ghi nhận trong hệ thống luật hợp đồng Việt Nam khá tương thích với pháp luật thế giới. Tuy nhiên, do không được quy định rõ ràng [23] nên có thể xem sự can thiệp của cơ quan nhà nước có thẩm quyền gây trở ngại đến việc thực hiện hợp đồng tại điểm d khoản 1 Điều 294 Luật Thương mại năm 2005 tương tự như "trở ngại" được quy định tại Điều 79(1) CISG bởi yếu tố "các bên không thể biết được vào thời điểm giao kết hợp đồng". Tuy nhiên, miễn trách nhiệm bồi thường thiệt hại khi hành vi vi phạm hợp đồng của một bên là do thực hiện quyết định của cơ quan quản lý nhà nước có thẩm quyền cũng có thể được xem là thuộc căn cứ miễn trách do việc không thực hiện đúng hợp đồng được quy định tại Điều 79(2) CISG miễn trách nhiệm bồi thường thiệt hại do lỗi của người thứ ba.

Từ những phân tích nêu trên có thể nhận thấy, nguyên tắc bồi thường thiệt hại nói chung và nguyên tắc bồi thường thiệt hại do vi phạm hợp đồng nói riêng được ghi nhận trong luật hợp đồng Việt Nam là khá tương đồng với các hệ thống pháp luật trên thế giới. Luật hợp đồng Việt Nam dựa trên nguyên tắc tự do ý chí, cho phép các bên thỏa thuận về điều khoản miễn trách nhiệm bồi thường thiệt hại. Theo đó, khi các bên tham gia xác lập hợp đồng đạt được thỏa thuận về miễn trách nhiệm bồi thường thiệt hại thì thỏa thuận đó sẽ có hiệu lực đối với các bên. Tuy nhiên, quy định về thỏa thuận miễn trách nhiệm bồi thường thiệt hại trong luật hợp đồng Việt Nam còn thiếu chặt chẽ bởi không đặt ra giới hạn đối với thỏa thuận miễn trách nhiệm bồi thường thiệt hại của các bên và do đó có thể gây ra sự bất công cho một bên khi bên được miễn trách nhiệm lợi dụng điều khoản này cố ý vi phạm hợp đồng. Tham khảo kinh nghiệm quốc tế cho thấy việc đặt ra giới hạn đối với miễn trách nhiệm dựa trên thỏa thuận là hết sức cần thiết bởi điều này cho phép bảo vệ cân bằng hơn lợi ích của các bên cũng như loại bỏ được việc bên có nghĩa vụ lợi dụng điều khoản này để cố ý vi phạm hợp đồng hoặc không cẩn trọng trong quá trình thực hiện hợp đồng. Như vậy sẽ là hoàn thiện hơn nếu Bộ luật Dân sự năm 2015 bổ sung thêm quy định một mặt thừa 
nhận quyền thỏa thuận về miễn trách nhiệm của các bên trong hợp đồng, mặt khác đặt ra giới hạn đối với trường hợp này.

\section{Tài liệu tham khảo}

[1] Christian Larroumet. Droit civil- Les obligationsLes contrat. 4e édition. Economica.1998. P713, 714; François Terré, Philippe Simler, Yves Lequette. Droit civil - Les obligations. 11e edition. Dalloz. 2013. P.649.

[2] Thomas D. Musgrave. Comparative Contractual Remedies. University of Western Australia Law Review. 2009. P.356.

[3] D. H. Peek. Athens-McDonald v. Kazis Contract-damages-mental injury. Adelaide law review. 1972. P.466.

[4] Lê Nết. Góp ý Dự thảo BLDS (sửa đổi) về điều khoản miễn trừ trách nhiệm và hạn chế quyền lợi trong hợp đồng. Tạp chí Khoa học pháp lý. Số 2. 2005.

[5] Ndubuisi Augustine nwafor. Comparative and Critical Analysis of the Doctrine of Exemption/Frustration/Force Majeure under the United Nations Convention on the Contract for International Sale of Goods, English Law and UNIDROIT Principles. Thesis Doctor of Philosophy. Stirling. Scotland. MARCH 2015 P.193.

https://dspace.stir.ac.uk/bitstream/1893/21805/1/D R\%20NWAFOR\%20N.\%20A.pdf ngày truy cập 17.4.2017.

[6] Dương Anh Sơn. Luật hợp đồng thương mại quốc tế. Nxb ĐHQG TPHCM. 2016. Tr. 113.

[7] Dương Anh Sơn. Luật hợp đồng thương mại quốc tế. Nxb ĐHQG TPHCM. 2016. Tr. 112.

[8] UNIDROIT Principles of International Commercial Contracts 2010 (2011). International institute for the Unification of Private Law (UNIDROIT). P. 235.

[9] Điều 80 CISG, Điều 7.1.2 UPICC và Điều 8:101 PECL.
[10] Xem Điều 79 CISG.

[11] Ingeborg Schwenzer. Force majeure and hardship in International Sales contracts. 2008. VUWLR. P.713, 720; Rodrigo Momberg Uribe. Change Circumstances in the International instruments of contract law - the approach of CISG, PICC, PECL and DCFR. P. 241, 242. www.cisg.law.pace.edu/cisg/biblio/uribe.pdf;

Roberto Pirozzi. Developments in the change of economic circumstances debate? 2012. VJ. P. 109 ;

[12] UNIDROIT Principles of International Commercial Contracts 2010 (2011). International institute for the Unification of Private Law (UNIDROIT). P. 217.

[13] Christoph Brunner. Force Majeure and Hardship under General Contract Principles - Exemption for Non-Performance in International Arbitration. Kluwer Law International. 2009. P 392.

[14] Christian Larroumet. Droit civil- Les obligationsLes contrat. 4e édition. Economica.1998. P.777801.

[15] Điều 1195 Sắc lệnh số 2016-131.

[16] Điều 1218 Sắc lệnh số 2016-131.

[17] Michael Maggi. Review of the Convention on Contracts for the International Sale of Goods (CISG). 2002-2003. Kluwer law international. P 306-308.

[18] Caslav Pejovic. Civil law and Common Law: Two different paths leading to the same goal. (2001) 32 VUWLR. 824.

[19] Thomas D. Musgrave. Comparative Contractual Remedies. University of Western Australia Law Review. 2009. P. 350.

[20] Điều 351 khoản 2 BLDS 2015, Điều 294 khoản 1 điểm b LTM 2005.

[21] Điều 351 khoản 3, Điều 363 BLDS 2015, Điều 294 khoản 1 điểm c LTM 2005.

[22] Điều 294 khoản 1 điểm d LTM 2005.

[23] Dương Anh Sơn. Luật hợp đồng thương mại quốc tế. Nxb ĐHQG TPHCM. 2016. Tr. 110. 


\title{
Damages for Breach of Contract: Principle of Full Compensation
}

\author{
Bui Thi Thanh Hang \\ VNU School of Law, 144 Xuan Thuy, Cau Giay, Hanoi, Vietnam
}

\begin{abstract}
The principle of full compensation is derived from the principle of pacta sunt servanda. According to this internationally recognized principle, the injured party is entitled to be fully compensated for all damages he/she suffered. This article researches on the principle of full compensation and its exceptions.

Keywords: The principle of full compensation, the principle of pacta sunt servanda, Vietnam Civil Code 2015.
\end{abstract}

